forthcoming report which is to be presented to H.M. Government by the Standing Commission on Museums and Art Galleries. It is anticipated that the report will be available in the late autumn and that it will be intimately associated with the recently established Area Museum Councils. Reference was also made to the continued generosity and interest of the Carnegie U.K. Trust, new regulations for the training of curators and technicians, and the new format of the Museums Journal. Diplomas and technical certificates were presented to the successful candidates in the recent examinations, and Dr. D. A. Allan, Sir George Dyson and Dr. F. J. North were electod to Honorary Fellowship. Alderman H. Barks and Dr. Barnett Stross were elected as institutional councillors, and Miss Anne Buck, Mr. A. A. Cumming, Mr. T. H. Scrutton and Mr. H. R. Singleton were elected as professional councillors. Sir Trenchard Cox was clected president for 1962-63, and the invitation of the University and City to hold the 1963 meeting at Newcastle upon Tyne at the end of July was accepted with thanks. In Belgium, visits were made to the museums and art galleries in Antwerp, Limburg, Brussels, Tornai, Halle, Ghent, Bruges and Liège. Opportunity was also taken to visit various historical buildings in the same places. The annual dinner of the Association was held at the Hotel Metropole in Brussels.

\section{The Institute of Applied Science of Victoria}

THE report of activities of the Institute of Applied Science of Victoria for the year ended June 30, 1961, comprises the report of the Trustees and the report of the director, Dr. C. M. Focker, both of which refer to a donation for the establishment of a planetarium (Pp. 24. Melbourne: Institute of Applied Science of Victoria. 1962). The Radiocarbon Dating Laboratory was opened in May $196 \mathrm{I}$; some seven age determinations have been completed and the equip. ment has functioned well. Completion of the new wing offered a major increase in display and working space and visitors are expected to exceed 400,000 annually when the planetarium is operating. Longterm displays noted by the director include some on decimal currency, Edwin Land's sodium mirror, solar batteries, radioactivity and the Trevithick highpressure steam engine.

\section{Microdoc}

Microdoc, the journal of the Council on Microphotography and Document Reproduction, the first number of which is commendably concise and to the point, is intended to keep members abreast of progress and events, as well as provide a forum for the research article, the review, the query and the complaint $(1$, No. 1. Edited by Mark Patterson. Pp. 16. London: The Library Association, 1962. Subscription (non-members) $30 s$. per annum). In this number, Mr. L. L. Ardern writes briefly on the opaque versus the translucent screen and on the Dagmer Super Reader as well as contributing a review of Mr. G. U. Davison's Microtext: Review of Progress in 1960. Mr. E. F. Patterson describes the new 'V.C. Executive Reader', and Mr. L. Corbett the 'AO Micro Opaque Reader', and Dr. L. A. Sayce's address at the meeting in October 1960 which voted in favour of establishing an advisory council on microphotography and document reproduction is reproduced. Altogether, the first issue of this new venture gives a very pleasing impression of purpose and performance.

\section{British Chemicals and their Manufacturers}

THE Association of British Chemical Manufacturers has recently issued the 1962 Supplement to the 1961 edition of the Association's Directory, British Chemicals and their Manufacturers (see Nature, 192, $1025 ; 1961)$. The Directory is published at twoyearly intervals, and during this period there are inevitably many changes and additions in the list of products manufactured. This Supplement provides full details of these changes and will ensure that users of the 1961 Directory have up-to-date information regarding manufacturers of chemicals in the United Kingdom. In order to assist users, a new lay-out and format have been adopted so that the information contained therein may be incorporated in the main Directory if so desired. As in the case of the Directory, the Supplement is available gratis to all firms and persons interested in the purchase of chemicals and allied products (Pp. 29. London: Association of British Chemical Manufacturers, 1962).

\section{Guide for Families of those in Mental Hospitals}

To most people the realization that a relative or close friend is mentally ill and needs hospital treatment comes as a grief and a shock. To help people faced with this situation, the National Association for Mental Health has produced a booklet of simple explanation and practical advice (price 2s.). It replaces a publication issued some years ago before the new Mental Health Act made it possible for mental illness to be treated with as little formality in most cases as physical illness. The booklet explains what kinds of help are available to patients and their families from the family doctor to the staffs of clinics and hospitals and workers in the local authority services. A brief summary of legal provisions is added as an appendix, with a glossary of some terms used in connexion with mental illness, a reading list and a list of local voluntary mental health associations existing in different areas.

\section{Chemistry and Mental Disease}

A sxmposium on "Chemistry and Mental Disease", arranged by the Royal Institute of Chemistry, the Chemical Society and the Society of Chemical Industry, will be held in the University of Manchester on September 26. The programme will include: biochemical processes in relation to mental disease (Dr. A. Todrick); inborn metabolic errors and mental disease (Dr. L. I. Woolf); pharmacological assessment of psychotropic activity (Dr. M. W. Parkes); tranquillizers-structure and activity relationships (Dr. A. F. Crowther); psychostimulantsstructure and activity (Dr. E. H. P. Young); use of modern drugs in psychiatric practice (Dr. F. A. Jenner). Further information can be obtained from Mr. H. H. Armstrong, Science Department, Stockport College for Further Education, Wellington Road South, Stockport.

\section{The Jane Coffin Childs Memorial Fund for Medical Research}

Tre Jane Coffin Childs Memorial Fund for Medical Researeh has recently announced that during the past year twenty-eight grants-in-aid and twentythree postdoctoral fellowships were awarded, totalling $382,459.85$ dollars. The Fund supports investigations in the fundamental aspects of neoplastic growth, and awards postdoctoral fellowships to candidates of outstanding potential in the same field. Applications for grants-in-aid are reviewed by the Board of 